\title{
Red blood cell transfusion in patients with traumatic brain injury: a systematic review protocol
}

Amélie Boutin 1,2, Michaël Chassée ${ }^{2,3,4}$, Michèle Shemilt² ${ }^{2}$ François Lauzier ${ }^{2,3,4}$, Lynne Moore ${ }^{1,2}$, Ryan Zarychanski ${ }^{5}$, Jacques Lacroix 6 , Dean A Fergusson ${ }^{7}$, Philippe Desjardins ${ }^{3}$ and Alexis F Turgeon ${ }^{2,3^{*}}$

\begin{abstract}
Background: Anemia is a prevalent condition in critically ill patients and red blood cell transfusions are frequent. Although transfusions at low hemoglobin levels have been shown to be associated with equivalent or better outcomes than higher hemoglobin thresholds, clinical equipoise persists in patients with traumatic brain injury considering their susceptibility to secondary cerebral insults such as those from hypoxemia.

Methods: Our objectives are to estimate the frequency of red blood cell transfusion in patients with traumatic brain injury and to evaluate transfusion thresholds, determinants and outcomes associated with transfusion strategies.

We will conduct a systematic review of cohort studies and randomized controlled trials of patients with traumatic brain injury. We will search MEDLINE, Embase, BIOSIS and the Cochrane Library for eligible studies. Two independent reviewers will screen all identified references. Studies including adult patients with traumatic brain injury reporting data on red blood cell transfusions will be eligible. We will collect data on baseline demographics, trauma characteristics, hemoglobin thresholds, blood transfusions and clinical outcomes (mortality, length of stay, complications, and so on). Two independent reviewers will extract data using a standardized form. We will pool cumulative incidences using DerSimonian and Lair random-effect models after a Freeman-Tukey transformation to stabilize variances. We will pool risk ratios or mean differences with random-effect models and Mantel-Haenszel or inverse variance methods in order to evaluate the association between red blood cell transfusion and potential determinants or outcomes. Sensitivity and subgroup analysis according to timing of red blood cell transfusion, traumatic brain injury severity, year of conduction of the study, risk of bias, notably, are planned.
\end{abstract}

Discussion: We expect to observe high heterogeneity in the proportion of transfused patients across studies and that the global proportion will be similar to the frequency observed in the general medical critically ill population. Our systematic review will allow us to better describe and understand current transfusion practices in patients with traumatic brain injury, a clinical population in which liberal transfusions are still advocated in the absence of evidence-based data.

\section{Systematic review registration: PROSPERO: CRD42014007402.}

Keywords: Red blood cells transfusion, Blood products, Traumatic brain injuries

\footnotetext{
* Correspondence: alexis.turgeon@fmed.ulaval.ca

${ }^{2}$ Centre Hospitalier Universitaire (CHU) de Québec Research Center,

Population Health and Optimal Health Practices Research Unit,

Traumatology-Emergency-Critical Care Medicine, Université Laval, Québec,

QC, Canada

${ }^{3}$ Division of Critical Care Medicine, Department of Anesthesiology and

Critical Care Medicine, Université Laval, Québec, QC, Canada

Full list of author information is available at the end of the article
}

\section{Biomed Central}

(c) 2014 Boutin et al.; licensee BioMed Central Ltd. This is an Open Access article distributed under the terms of the Creative Commons Attribution License (http://creativecommons.org/licenses/by/4.0), which permits unrestricted use, distribution, and reproduction in any medium, provided the original work is properly credited. The Creative Commons Public Domain Dedication waiver (http://creativecommons.org/publicdomain/zero/1.0/) applies to the data made available in this article, unless otherwise stated. 


\section{Background}

Red blood cell transfusion is a core topic in critical care medicine. Transfusion practices in the overall nonbleeding medical and surgical intensive care population have been extensively described [1,2]. Studies have evaluated hemoglobin thresholds for transfusion in critically ill patients [3-13] and have shown that restrictive transfusion strategies (hemoglobin thresholds between 7 and $9 \mathrm{~g} / \mathrm{dL}$ ) are as safe as liberal strategies (thresholds between 9 and $12 \mathrm{~g} / \mathrm{dL})[3,4]$. However, specific patient populations, such as neurocritically ill patients, were underrepresented in these studies and results could thus not be applied to them. Indeed, given the vulnerability of the brain to secondary hypoxic insults, concerns have been raised regarding the safety and efficacy of restrictive transfusion strategies in the presence of traumatic brain injuries [14]. Two recent guidelines in a neurocritically ill patient population (subarachnoid hemorrhage) were published; one recommending to treat anemia but noting that thresholds were to be determined, and the other recommending transfusion in order to reach hemoglobin levels of 80 to $100 \mathrm{~g} / \mathrm{L}[15,16]$. Interestingly, guidelines for the management of patients with traumatic brain injury did not cover the topic [17]. A recent systematic review highlighted the paucity of data regarding the adoption of liberal or restrictive strategies in this specific population [18] and no consensus has been reached on appropriate transfusion thresholds [19]. Considering the high mortality in critically ill patients with traumatic brain injury [20], the potential impact of red blood cells transfusion on clinical outcomes and the uncertainty regarding optimal transfusion strategies in patients with acute neurologic lesions, current transfusion practices must be described in order to inform future clinical trials evaluating transfusion strategies in this population.

\section{Objectives}

We first aim to evaluate current practices regarding red blood cell transfusion in critically ill patients with traumatic brain injuries by estimating the frequency of red blood cell transfusion in these patients. Secondly, we seek to evaluate transfusion thresholds, determinants and outcomes associated with transfusion strategies.

\section{Methods}

We propose to conduct a systematic review of cohort studies and randomized control trials reporting transfusions in patients with traumatic brain injury during their acute hospital stay.

\section{Protocol and registration}

The protocol of the review is registered in PROSPERO (www.crd.york.ac.uk/prospero) CRD42014007402.

\section{Study design}

We will conduct a systematic review in accordance with the Preferred Reporting Items for Systematic Reviews and Meta-Analyses (PRISMA) statement [21] and The Cochrane Handbook for Systematic Reviews of Interventions [22] methodological recommendations.

\section{Eligibility criteria}

Since we are interested in the frequency of red blood cell transfusion and its determinants, our systematic review will include prospective and retrospective cohort studies, and randomized controlled trials. Patients suffering from a traumatic brain lesion (any severity) will be considered. In case of a mixed population, at least $80 \%$ of patients included in a specific study have to respect this criterion for the study to be eligible. Since we expect that few studies will report precisely if patients were recruited at hospital admission or intensive care unit (ICU) admission, we will not restrict inclusion to critically ill patients but rather consider a population-based approach of acute care hospital admissions. Studies and trials will have to report data on red blood cell transfusion frequency. Studies who specifically studied patients with blood disorders and coagulopathies will be excluded. Table 1 and Table 2 present the structured study question and inclusion and exclusion criteria, respectively.

\section{Information sources}

We will systematically search MEDLINE, Embase, BIOSIS and The Cochrane Library (from their inception up to a maximum of nine months before submission for publication) for eligible studies. References of included articles and abstracts of major conferences will be screened to identify additional potentially eligible studies. Experts in neurocritical care medicine, not members

\section{Table 1 Structured question}

\begin{tabular}{|c|c|}
\hline Population & - adult patients with traumatic brain injury \\
\hline Intervention & - red blood cell transfusion \\
\hline Comparator & - no transfusion \\
\hline $\begin{array}{l}\text { Primary } \\
\text { outcome }\end{array}$ & - frequency of red blood cell transfusion \\
\hline \multirow{8}{*}{$\begin{array}{l}\text { Secondary } \\
\text { outcomes }\end{array}$} & - transfusion thresholds \\
\hline & - number of red blood cell units transfused \\
\hline & - determinants of red blood cell transfusion \\
\hline & - mortality \\
\hline & - frequency of withdrawal of life-sustaining therapy \\
\hline & - frequency of unfavourable neurological outcome \\
\hline & - ICU and hospital length of stay \\
\hline & - all other reported clinical outcomes \\
\hline Study design & $\begin{array}{l}\text { - cohort studies (both prospective and retrospective) } \\
\text { and randomized controlled trials }\end{array}$ \\
\hline
\end{tabular}




\section{Table 2 Study eligibility criteria}

\begin{tabular}{ll}
\hline $\begin{array}{l}\text { Inclusion } \\
\text { criteria }\end{array}$ & - Prospective study, retrospective cohort study or \\
& randomized controlled trials \\
& - Acute setting \\
& - At least $80 \%$ of patients suffering from an acute \\
& - At least $80 \%$ of adults patients ( $\geq 18$ years old) \\
& - Data on red blood cell transfusion reported \\
Exclusion & - Sample of patients with congenital hereditary blood \\
criteria & disorders (example: sickle cell disease, $\beta$-thalassemia) \\
& - Sample of patients with coagulation disorders (example: \\
& hemophilia, thrombotic thrombocytopenic purpura, \\
& Von Willebrand disease)
\end{tabular}

of our team, will also be contacted to identify additional ongoing studies. We will request available transfusion data from investigators of retrieved studies if deemed necessary.

\section{Search strategy}

Our search strategy will be based on keywords related to transfusion and anemia, as well as traumatic brain injury. Clinicians, investigators with expertise in transfusion or in neurocritical care, and information specialists will be consulted to verify the search strategy, identify synonyms and additional search terms. Relevant index terms (Medical Subject Headings and Emtree) will be added to the strategy. The search will be limited to human studies [22]. No language or date of publication restriction will be used. The search strategy will be first designed for Medline and Embase, and will be adapted for other electronic databases afterwards. The current version of our Medline search strategy is presented in Additional file 1. This preliminary strategy has been tested through an iterative process in order to achieve sufficient specificity while maintaining high sensitivity. Results will be imported in EndNote (version X7.0.1, New York City: Thomson Reuters, 2011) and duplicates will be removed. References will then be exported to a Microsoft Excel (version 14.1.0, Redmond, WA: Microsoft, 2011) spreadsheet in order to complete the selection process.

\section{Study selection}

Two independent reviewers will screen all identified references to determine eligibility, first from titles and abstracts, and then based on full text evaluation for studies that could be potentially eligible. In case of disagreement on the inclusion of a study, a third reviewer will be consulted. In case the blood product transfused is not clearly specified, authors will be contacted to ensure that reported data pertains to red blood cell transfusion.

A translation of non-English or non-French articles will be obtained. Agreement on study selection will be evaluated with a kappa coefficient. Considering the high sensitivity of the search strategy, we expect the kappa will indicate moderate agreement. In case the agreement is too low, indicating an evasive interpretation of eligibility criteria, a third reviewer will review records' titles and abstracts.

\section{Data collection process}

A preliminary version of the abstraction form will be pilot-tested and customized by two reviewers using four publications. Two independent reviewers will abstract data using the standardized form. In case of discrepancy, consensus will be reached with the involvement of a third reviewer. Authors will be contacted if relevant data is missing or clarification is needed.

\section{Data items}

Data pertaining to study characteristics (design, date of completion, funding sources, and so on), patients' baseline characteristics (age, gender, type of neurological disease, severity of the lesion on admission, and so on), clinical management (surgical, medical), hemoglobin levels, blood products (type of products received, timing, quantity, repetition, thresholds, and so on), co-interventions (type, timing), clinical outcomes (mortality and withdrawal of lifesustaining therapies and their timing, length of hospital and ICU stay, neurological outcome (any scale; for example, Glasgow Outcome Score (GOS)), complications, and so on) [Additional file 2] will be extracted from published reports.

\section{Risk of bias in individual studies}

Risk of bias of included RCTs will be assessed using The Cochrane Collaboration tool for assessing the risk of bias [22]. Risk of bias in cohort studies will be assessed using a pilot version of a new tool for the assessment of the risk of bias in non-randomized studies, currently under development by Cochrane's Non-Randomized Studies Methods Group.

\section{Summary measures}

We will report the cumulative incidence of transfusion in the course of hospital stay (primary outcome). Risk ratios of the association between red blood cell transfusion and potential determinants (categorical variables such as sex) or any relevant clinical outcomes, such as mortality, unfavorable neurological outcome, complications (any or specific complications, or categories of complications [23]), will be reported. Mean differences of potential determinants or outcomes (continuous or ordinal variables such as age, hemoglobin levels, severity of the traumatic brain injury, length of stay, and so on) according to transfusion status will be reported. We will compute mean transfusion thresholds as well as mean differences in number of units transfused according to 
outcomes when available. A two-sided 5\% type I error will be considered for all analyses.

\section{Synthesis of results}

If appropriate, results from cohort studies will be pooled with results from randomized controlled trials that did not randomize patients to specific transfusion strategies. Results from randomized controlled trials allocating patients to different transfusion strategies will be pooled separately, if deemed appropriate.

Variances of cumulative incidences of transfusion from all studies will be stabilized using a Freeman-Tukey transformation [24] and proportions will be pooled with DerSimonian and Laird random-effects approach [25] using $\mathrm{R}$ statistical software (version 2.15.1: R Core Team, R Foundation for Statistical Computing June 2012, Vienna, Austria). Means and mean differences will be pooled with inverse variance method with random effects. Risk ratio analyses will be conducted with Review Manager (RevMan) (version 5.1, Copenhagen: The Nordic Cochrane Centre, The Cochrane Collaboration, 2012) using Mantel-Haenszel random-effect models. Pooled effect sizes and their 95\% confidence limits will be reported.

Statistical heterogeneity will be measured using the Cochran's $Q$-test and $\mathrm{I}^{2}$ statistics [26], the latter being interpreted as low from 0 to $40 \%$, moderate from 30 to $60 \%$, substantial from 50 to $90 \%$ and considerable from 75 to $100 \%$ [22].

\section{Risk of bias}

We will evaluate the risk of publication bias by visual exploration of funnel plots. We will also evaluate the risk of selective reporting of outcomes within studies by searching for previously published protocols on registration website (www.controlled-trials.com and clinicaltrials.gov).

The ability of a study to answer the review question will be evaluated in terms of applicability. Applicability concerns relate to deviation of a study from the ideal study designed to answer our research question (in relation to our primary outcome). For instance, a study recruiting patients with any severity of traumatic brain injury at hospital admission, therefore including patients with mild traumatic brain injury that might not be admitted to an ICU, will be considered as having high applicability concerns.

\section{Additional analyses}

\section{Sensitivity analyses}

To assess the strength of observed associations, a priori sensitivity analyses are planned to explore potential heterogeneity according to the following factors: severity of the brain injury (moderate or severe traumatic brain injury; severe only, defined as Glasgow Coma Scale $(G C S)<$
9 or according), type of blood product given as a cointervention (platelets, plasma, whole blood, and so on), risk of bias (low risk of bias), low applicability concerns, design of studies (cohort versus randomized controlled trials), presence of comorbidities (by categories of comorbidities [27] if data available) and year of publication (after 1999, year of the TRICC trial publication [5]). A sensitivity analysis will also be conducted taking into account if outcomes were reported as primary or secondary outcomes.

\section{Subgroup analyses}

Subgroup analyses to assess clinical heterogeneity are also planned to evaluate timing of intervention (emergency, ICU, overall hospital stay or other timing), time spent in the ICU or hospital, amount of blood transfused, surgery or specific pharmacological interventions, volume replacement, active bleeding and CRASH and IMPACT scores.

\section{Meta-regression}

If the number of eligible studies is sufficient (at least ten studies by covariate), we also plan on conducting a meta-regression analysis; first, modeling mean values of multiple determinants at study level with the reception of a transfusion; secondly, transfusion and factors associated with mortality in traumatic brain injury (for example, age and GCS) with mortality.

\section{GRADE of evidences}

We will use the GRADE methodology to evaluate the quality of evidences (www.gradeworkinggroup.org) of our findings [28].

\section{Discussion}

\section{Expected benefits}

This project will allow the knowledge synthesis regarding transfusion practices in patients with traumatic brain injury. Considering the paucity of data and the equipoise on the optimal transfusion strategy in this population, it is of major importance to assess current practices. Therefore, this project, in addition to our previous systematic review of comparative studies, will systematically group original research data on the topic of red blood cell transfusion in traumatic brain injury.

\section{Inform future studies}

Considering the observed lack of evidence from comparative studies and the risk of bias associated with observational studies, we expect results to be heterogeneous. Our results will provide information to inform the design of further studies in traumatic brain injury and red blood cells transfusion. Ultimately, we will obtain critical data regarding transfusion practices in patients with traumatic brain 
injury that will allow us to better design a high-quality noninferiority trial. For example, information on the frequency of transfusion among patients with traumatic brain injury will facilitate the calculation of sample size estimates and recruitment rates. The knowledge of the usual hemoglobin thresholds observed in patients with traumatic brain injury and those associated with better outcomes will help setting acceptable, plausible and realistic comparative thresholds in a future trial.

\section{Limitations}

Despite the use of rigorous methodology, we do expect high statistical and clinical heterogeneity in our analyses and few studies of low risk of bias. The strength of our conclusions may thus be limited by those factors. We may uncover only a limited number of comparative studies of transfusion strategies that included a small number of patients. This may potentially limit the planned sensitivity and subgroup analyses. In addition, we will conduct analysis of potential determinants and outcomes associated with transfusion through univariate analysis. In cohort studies, univariate analyses of associations are prone to confusion bias. If sufficient data are available, we will construct a metaregression, which will help to, at least partially, control for potential confusion.

Little is known on optimal red blood cell transfusion strategies in patients with traumatic brain injury. In order to design studies to improve clinical practices, evidencebased information has to be gathered. We propose to conduct a systematic review that will synthesize the current knowledge from published clinical studies in the field. Our results will be used to optimize future prospective studies on this topic in order to conduct high-quality and rigorous studies with the aim of increasing the quality of care received by patients with traumatic brain injury.

\section{Additional files}

Additional file 1: Search strategy for MEDLINE/PubMed.

Additional file 2: Outcome variables.

\section{Abbreviations}

CRASH: Corticosteroid randomization after significant head injury; GCS: Glasgow Coma Scale; GOS: Glasgow Outcome Scale; GRADE: Grading of Recommendations Assessment Development and Evaluation; ICU: Intensive care units; IMPACT: International Mission for Prognosis and Analysis of Clinical Trials in TBI; PRISMA: Preferred Reporting Items for Systematic Reviews and Meta-Analyses; RCT: Randomized controlled trial; TRICC: Transfusion Requirements in Critical Care.

\section{Competing interests}

The authors declare that they have no competing interests.

\section{Authors' contributions}

$A B$ made substantial contributions to conception and design of the review and drafted the manuscript, has given final approval of the version to be published and agreed to be accountable for all aspects of the work. AFT, $M C, M S, F L, L M, R Z, J L, D A F$ and PD contributed to the discussion over the conception and design of the review, revised the manuscript critically for important intellectual content, have given final approval of the version to be published and agree to be accountable for all aspects of the work.

\section{Acknowledgement}

We would like to thank Marie-Joëlle Poitras-Pariseau, information specialist at Université Laval, for her help in the development of the search strategy.

\section{Funding}

This study is funded by personal funds. Ms. Boutin is recipient of a Doctoral Research Award (Doctoral Award - Frederick Banting and Charles Best Canada Graduate Scholarships) from the Canadian Institutes for Health Research (CIHR). Drs Turgeon and Lauzier are recipients of a research career award from the Fonds de Recherche Québec - Santé (FRQ-S) and are supported by the Traumatology Research Consortium of the FRQ-S. Drs Moore is a recipient of a New Investigator Award from the CIHR. Dr Zarychanski is a recipient of an $\mathrm{RCT}$ mentorship award from the $\mathrm{CIHR}$.

\section{Author details}

${ }^{1}$ Department of Social and Preventive Medicine, Université Laval, Québec, QC, Canada. ${ }^{2}$ Centre Hospitalier Universitaire (CHU) de Québec Research Center, Population Health and Optimal Health Practices Research Unit, Traumatology-Emergency-Critical Care Medicine, Université Laval, Québec, QC, Canada. ${ }^{3}$ Division of Critical Care Medicine, Department of Anesthesiology and Critical Care Medicine, Université Laval, Québec, QC, Canada. ${ }^{4}$ Department of Medicine, Université Laval, Québec, QC, Canada. ${ }^{5}$ Department of Internal Medicine, Sections of Critical Care Medicine of Hematology and of Medical Oncology, University of Manitoba, Winnipeg, MB, Canada. ${ }^{6}$ Department of Pediatrics, Critical Care Medicine, Université de Montréal, Montréal, QC, Canada. ${ }^{7}$ Clinical Epidemiology Unit, Ottawa Hospital Research Institute, Ottawa, ON, Canada.

Received: 14 February 2014 Accepted: 19 May 2014

Published: 18 June 2014

\section{References}

1. Corwin HL, Gettinger A, Pearl RG, Fink MP, Levy MM, Abraham E, Maclntyre NR, Shabot MM, Duh MS, Shapiro MJ: The CRIT study: anemia and blood transfusion in the critically ill - current clinical practice in the United States. Crit Care Med 2004, 32:39-52.

2. Vincent JL, Baron JF, Reinhart K, Gattinoni L, Thijs L, Webb A, Meier-Hellmann A, Nollet G, Peres-Bota D: Anemia and blood transfusion in critically ill patients. JAMA 2002, 288:1499-1507.

3. Marik PE, Corwin HL: Efficacy of red blood cell transfusion in the critically ill: a systematic review of the literature. Crit Care Med 2008, 36:2667-2674.

4. Carson JL, Carless PA, Hebert PC: Transfusion thresholds and other strategies for guiding allogeneic red blood cell transfusion. Cochrane Database Syst Rev 2012, 4:CD002042.

5. Hebert PC, Wells G, Blajchman MA, Marshall J, Martin C, Pagliarello G, Tweeddale M, Schweitzer I, Yetisir E: A multicenter, randomized, controlled clinical trial of transfusion requirements in critical care. Transfusion requirements in critical care investigators, Canadian critical care trials group. N Engl J Med 1999, 340:409-417.

6. Lacroix J, Hebert PC, Hutchison JS, Hume HA, Tucci M, Ducruet T, Gauvin F, Collet JP, Toledano BJ, Robillard P, Joffe A, Biarent D, Meert K, Peters MJ: Transfusion strategies for patients in pediatric intensive care units. N Engl J Med 2007, 356:1609-1619.

7. Gajic O, Dara SI, Mendez JL, Adesanya AO, Festic E, Caples SM, Rana R, St Sauver JL, Lymp JF, Afessa B, Hubmayr RD: Ventilator-associated lung injury in patients without acute lung injury at the onset of mechanical ventilation. Crit Care Med 2004, 32:1817-1824.

8. Gong MN, Thompson BT, Williams P, Pothier L, Boyce PD, Christiani DC: Clinical predictors of and mortality in acute respiratory distress syndrome: potential role of red cell transfusion. Crit Care Med 2005, 33:1191-1198.

9. Khan H, Belsher J, Yilmaz M, Afessa B, Winters JL, Moore SB, Hubmayr RD Gajic O: Fresh-frozen plasma and platelet transfusions are associated with development of acute lung injury in critically ill medical patients. Chest 2007, 131:1308-1314. 
10. Shorr AF, Duh MS, Kelly KM, Kollef MH: Red blood cell transfusion and ventilator-associated pneumonia: a potential link? Crit Care Med 2004, 32:666-674.

11. Shorr AF, Jackson WL, Kelly KM, Fu M, Kollef MH: Transfusion practice and blood stream infections in critically ill patients. Chest 2005, 127:1722-1728.

12. Taylor RW, O'Brien J, Trottier SJ, Manganaro L, Cytron M, Lesko MF, Arnzen K, Cappadoro C, Fu M, Plisco MS, Sadaka FG, Veremakis C: Red blood cell transfusions and nosocomial infections in critically ill patients. Crit Care Med 2006, 34:2302-2308. quiz 2309.

13. Zilberberg MD, Carter C, Lefebvre P, Raut M, Vekeman F, Duh MS, Shorr AF: Red blood cell transfusions and the risk of acute respiratory distress syndrome among the critically ill: a cohort study. Crit Care 2007, 11:R63.

14. Kramer AH, Zygun DA: Anemia and red blood cell transfusion in neurocritical care. Crit Care 2009, 13:R89.

15. Diringer MN, Bleck TP, Claude Hemphill J 3rd, Menon D, Shutter L, Vespa $P$, Bruder N, Connolly ES Jr, Citerio G, Gress D, Hanggi D, Hoh BL, Lanzino G, Le Roux P, Rabinstein A, Schmutzhard E, Stocchetti N, Suarez Jl, Treggiari M, Tseng MY, Vergouwen MD, Wolf S, Zipfel G, Neurocritical Care Society: Critical care management of patients following aneurysmal subarachnoid hemorrhage: recommendations from the neurocritical care Society's multidisciplinary consensus conference. Neurocrit Care 2011, 15:211-240.

16. Connolly ES Jr, Rabinstein AA, Carhuapoma JR, Derdeyn CP, Dion J, Higashida RT, Hoh BL, Kirkness CJ, Naidech AM, Ogilvy CS, Patel AB, Thompson BG, Vespa P, American Heart Association Stroke Council; Council on Cardiovascular Radiology and Intervention; Council on Cardiovascular Nursing; Council on Cardiovascular Surgery and Anesthesia; Council on Clinical Cardiology: Guidelines for the management of aneurysmal subarachnoid hemorrhage: a guideline for healthcare professionals from the American Heart Association/American Stroke Association. Stroke 2012, 43:1711-1737.

17. Brain Trauma Foundation, American Association of Neurological Surgeons, Joint section on neurotrauma and critical care: Guidelines for the management of severe traumatic brain injury. J Neurotrauma 2007, 24:S1-S106.

18. Desjardins P, Turgeon AF, Tremblay MH, Lauzier F, Zarychanski R, Boutin A, Moore L, McIntyre LA, English SW, Rigamonti A, Lacroix J, Fergusson DA: Hemoglobin levels and transfusions in neurocritically ill patients: a systematic review of comparative studies. Crit Care 2012, 16:R54.

19. Carson JL, Grossman BJ, Kleinman S, Tinmouth AT, Marques MB, Fung MK, Holcomb JB, Illoh O, Kaplan LJ, Katz LM, Rao SV, Roback JD, Shander A, Tobian AA, Weinstein R, Swinton McLaughlin LG, Djulbegovic B: Red blood cell transfusion: a clinical practice guideline from the AABB*. Ann Intern Med 2012, 157:49-58.

20. Turgeon AF, Lauzier F, Simard JF, Scales DC, Burns KE, Moore L, Zygun DA, Bernard F, Meade MO, Dung TC, Ratnapalan M, Todd S, Harlock J, Fergusson DA: Mortality associated with withdrawal of life-sustaining therapy for patients with severe traumatic brain injury: a Canadian multicentre cohort study. CMAJ 2011, 183:1581-1588.

21. Moher D, Liberati A, Tetzlaff J, Altman DG, Group P: Preferred reporting items for systematic reviews and meta-analyses: the PRISMA statement BMJ (Clinical research ed) 2009, 339:b2535.

22. Higgins JPT, Green S: Cochrane Handbook for Systematic Reviews of Interventions Version 5.1.0 [Updated March 2011]. The Cochrane Collaboration; 2011. Available from www.cochrane-handbook.org.

23. Moore L, Stelfox HT, Turgeon AF, Nathens AB, Le Sage N, Emond M, Bourgeois G, Lapointe J, Gagne M: Rates, patterns, and determinants of unplanned readmission after traumatic injury: a multicenter cohort study. Ann Surg 2014, 259:374-380.

24. Mills EJ, Nachega JB, Buchan I, Orbinski J, Attaran A, Singh S, Rachlis B, Wu P, Cooper C, Thabane L, Wilson K, Guyatt GH, Bangsberg DR: Adherence to antiretroviral therapy in sub-Saharan Africa and North America: a meta-analysis. JAMA 2006, 296:679-690.

25. DerSimonian R, Laird N: Meta-analysis in clinical trials. Control Clin Trials 1986, 7:177-188.
26. Higgins JP, Thompson SG, Deeks JJ, Altman DG: Measuring inconsistency in meta-analyses. BMJ (Clinical research ed) 2003, 327:557-560.

27. Charlson ME, Pompei P, Ales KL, MacKenzie CR: A new method of classifying prognostic comorbidity in longitudinal studies: development and validation. J Chronic Dis 1987, 40:373-383.

28. Guyatt GH, Oxman AD, Schunemann HJ, Tugwell P, Knottnerus A: GRADE guidelines: a new series of articles in the Journal of Clinical Epidemiology. J Clin Epidemiol 2011, 64:380-382

doi:10.1186/2046-4053-3-66

Cite this article as: Boutin et al: Red blood cell transfusion in patients with traumatic brain injury: a systematic review protocol. Systematic Reviews 2014 3:66.

\section{Submit your next manuscript to BioMed Central and take full advantage of:}

- Convenient online submission

- Thorough peer review

- No space constraints or color figure charges

- Immediate publication on acceptance

- Inclusion in PubMed, CAS, Scopus and Google Scholar

- Research which is freely available for redistribution

Submit your manuscript at www.biomedcentral.com/submit
C Biomed Central 